\title{
PENGARUH KAWASAN KONSERVASI PERAIRAN TERHADAP POPULASI IKAN KARANG DI PULAU AY DAN RHUN, KEPULAUAN BANDA, PROVINSI MALUKU
}

\section{IMPACT OF MARINE PROTECTED AREA ON REEF FISH POPULATION IN AY AND RHUN ISLANDS, BANDA ISLANDS, MALUKU PROVINCE}

\author{
Marthen Welly ${ }^{*}$, Achmad Fahrudin ${ }^{2}$, Dietriech G. Bengen ${ }^{3}$, \& Ario Damar ${ }^{2,4}$ \\ ${ }^{1}$ Program Studi Pengelolaan Sumberdaya Pesisir dan Lautan, IPB, Bogor, 16680, Indonesia \\ ${ }^{2}$ Departemen Manajemen Sumberdaya Perairan, FPIK-IPB, Bogor, 16680, Indonesia \\ ${ }^{3}$ Departemen Ilmu dan Teknologi Kelautan, FPIK-IPB, Bogor, 16680, Indonesia \\ ${ }^{4}$ Pusat Kajian Sumberdaya Pesisir dan Laut, IPB Bogor, 16680, Indonesia \\ *E-mail: mwelly@coraltrianglecenter.org
}

\begin{abstract}
The function of marine protected area (MPA) is to manage marine biodiversity and fisheries resources toward sustainability utilization. The reef fish condition is one of bioindicator to measure the MPA management impact. The purpose of this research was to study impact of Ay and Rhun Islands MPA establishment on the reef fish resources in the Banda Island, Maluku, Indonesia. The methods used for data collection were the Underwater Visual Census (UVC) and Fish Length Estimation supported with SCUBA equipment. Data analysis was operated by comparing secondary and primary data which included abundance, biomass, tropic level status and the composition of large fish and small fish from 10 target and economically important fish families, before and after Ay and Rhun Islands declared as $M P A$. The results presented that the abundance and biomass of reef fish were fluctuated temporally before and after Ay and Rhun Islands designated as MPA, however in good and high rating. Whereas the tropic level status and the composition of reef fish sizes changed before and after MPA designation, on the contrary, stationary in a balanced condition between tropic groups, large and small fish. The conclusion is Ay and Rhun Islands MPA have positive impact on the reef fish resources.
\end{abstract}

Keywords: bioindicators, management effectiveness, protected area, reef fish

\begin{abstract}
ABSTRAK
Kawasan konservasi perairan (KKP) berfungsi untuk mengelola sumber daya perikanan dan keanekaragaman hayati laut agar dapat dimanfaatkan secara berkelanjutan. Kondisi ikan karang merupakan salah satu bioindikator untuk mengukur dampak pengelolaan KKP. Tujuan dari penelitian ini adalah untuk melihat dampak pembentukan KKP Daerah (KKPD) Pulau Ay dan Pulau Rhun terhadap sumber daya perikanan karang di Kepulauan Banda, Maluku, Indonesia. Metode yang digunakan untuk pengumpulan data yaitu Underwater Visual Census (UVC) dan Fish Length Estimation dengan bantuan peralatan SCUBA. Analisis data dilakukan dengan membandingkan data sekunder dan data primer yang meliputi kelimpahan, biomassa, status tropik dan komposisi ukuran ikan besar dan ikan kecil dari 10 famili ikan target dan ekonomis penting sebelum dan sesudah Pulau Ay dan Pulau Rhun dicadangkan sebagai KKP. Hasil penelitian menunjukan bahwa kelimpahan dan biomassa ikan karang secara temporal berfluktuasi sebelum dan sesudah Pulau Ay dan Pulau Rhun dicadangkan sebagai KKP, namun masih dalam kondisi melimpah dan tinggi. Status tropik dan komposisi ukuran ikan karang berubah-ubah sebelum dan sesudah pencadangan KKP, namun masih dalam kondisi seimbang antar kelompok tropik, ikan besar dan ikan kecil. Kesimpulan penelitian ini adalah pencadangan KKPD memberikan dampak positif terhadap sumber daya ikan karang di Pulau Ay dan Pulau Rhun.
\end{abstract}

Kata kunci: bioindikator, efektivitas pengelolaan, ikan karang, kawasan konservasi 


\section{PENDAHULUAN}

Kawasan konservasi perairan (KKP) dibentuk dengan tujuan melindungi keanekaragaman hayati pesisir dan laut serta sumber daya perikanan sehingga dapat secara berkelanjutan memberikan manfaat bagi masyarakat (Hukom et al., 2019). KKP didefinisikan sebagai kawasan perairan yang dilindungi, dikelola dengan sistem zonasi untuk mewujudkan pengelolaan sumber daya ikan dan lingkungannya secara berkelanjutan (Peraturan Pemerintah Nomor 60, 2007). Indonesia berkomitmen untuk melindungi pesisir dan lautnya seluas 20 juta ha pada tahun 2020 melalui pembentukan KKP (Huffard et al., 2012).

Kawasan Konservasi Perairan Daerah (KKPD) Pulau Ay dan Pulau Rhun di Kepulauan Banda, Maluku merupakan salah satu KKP di Indonesia. KKPD Pulau Ay dan Pulau Rhun dicadangkan melalui Surat Keputusan Gubernur Maluku No. 338 Tahun 2016 dengan total luas 47.865 ha. Ekosistem terumbu karang yang merupakan habitat bagi ikan karang adalah salah satu target konservasi penting KKPD Pulau Ay dan Pulau Rhun. Menurut Welly et al. (2013), ditemukan 397 jenis karang dan 683 jenis ikan karang di Kepulauan Banda, termasuk Pulau Ay dan Pulau Rhun.

Kelimpahan dan biomassa ikan karang merupakan salah satu bioindikator yang digunakan untuk mengukur efektivitas pengelolaan KKP (Carter et al., 2010). Namun saat ini, perikanan ikan karang merupakan salah satu sumber mata pencaharian utama bagi masyarakat Pulau Ay dan Pulau Rhun selain hasil perkebunan Pala. Pola pemanfaatan ikan karang oleh masyarakat akan membawa dampak terhadap kondisi populasi ikan karang di kedua pulau tersebut. Perubahan populasi ikan karang di Pulau Ay dan Pulau Rhun sebagai akibat pemanfaatan dapat menjadi salah satu bioindikator penting untuk mengukur tingginya dampak pembentukan KKPD Pulau Ay dan Pulau Rhun dalam melindungi sumber daya perikanan dan lingkungannya (Skoglund, 2014).

Tujuan dari penelitian adalah untuk menganalisis kondisi populasi ikan karang secara spasial dan temporal di KKPD Pulau Ay dan Pulau Rhun dari aspek: 1) kelimpahan ikan karang; 2) biomassa ikan karang; 3) status tropik ikan karang berdasarkan biomassa; 4) ukuran panjang ikan yang dibagi dalam ikan besar $(\geq 35 \mathrm{~cm})$ dan ikan kecil $(<35 \mathrm{~cm})$.

\section{METODE PENELITIAN}

\subsection{Waktu dan Tempat}

Penelitian ini dilakukan pada bulan Oktober 2018 di KKPD Pulau Ay dan Pulau Rhun, Kepulauan Banda, Maluku. Penelitian ini dilakukan pada empat stasiun pengamatan (Figure 1 dan Table 1), yaitu Stasiun 1 Tanjung Noret (P. Rhun), Stasiun 2 Nailaka (P. Rhun), Stasiun 3 Batu Belang (Pulau Ay Barat), dan Stasiun 4 Batu Jatuh (Pulau Ay Utara).

\subsection{Bahan dan Data}

Data yang dikumpulkan dalam penelitian ini adalah data primer dan data sekunder. Data primer di dapatkan melalui pencatatan langsung di lapangan pada saat penelitian dilakukan. Data sekunder dikumpulkan dari hasil marine rapid assesment dan monitoring terumbu karang tahunan Coral Triangle Center (CTC) pada tahun 2012, 2015 dan 2017.

Penelitian ini menggunakan 10 famili ikan karang target dan ekonomis penting, yaitu Achanturidae (kulit pasir), Carangidae (kuwe), Haemulidae (bibir tebal), Labridae (napoleon), Lethrinidae (lencam), Lutjanidae (kakap), Scaridae (kakak tua), Serranidae (kerapu), Siganidae (baronang), dan Sphyraenidae (barakuda) (Allen \& Steene, 1996).

Data ikan karang dicatat dengan metode UVC dengan bantuan peralatan SCUBA, kertas anti air (newtop) dan pensil 2B (English et al., 1997). Estimasi panjang 


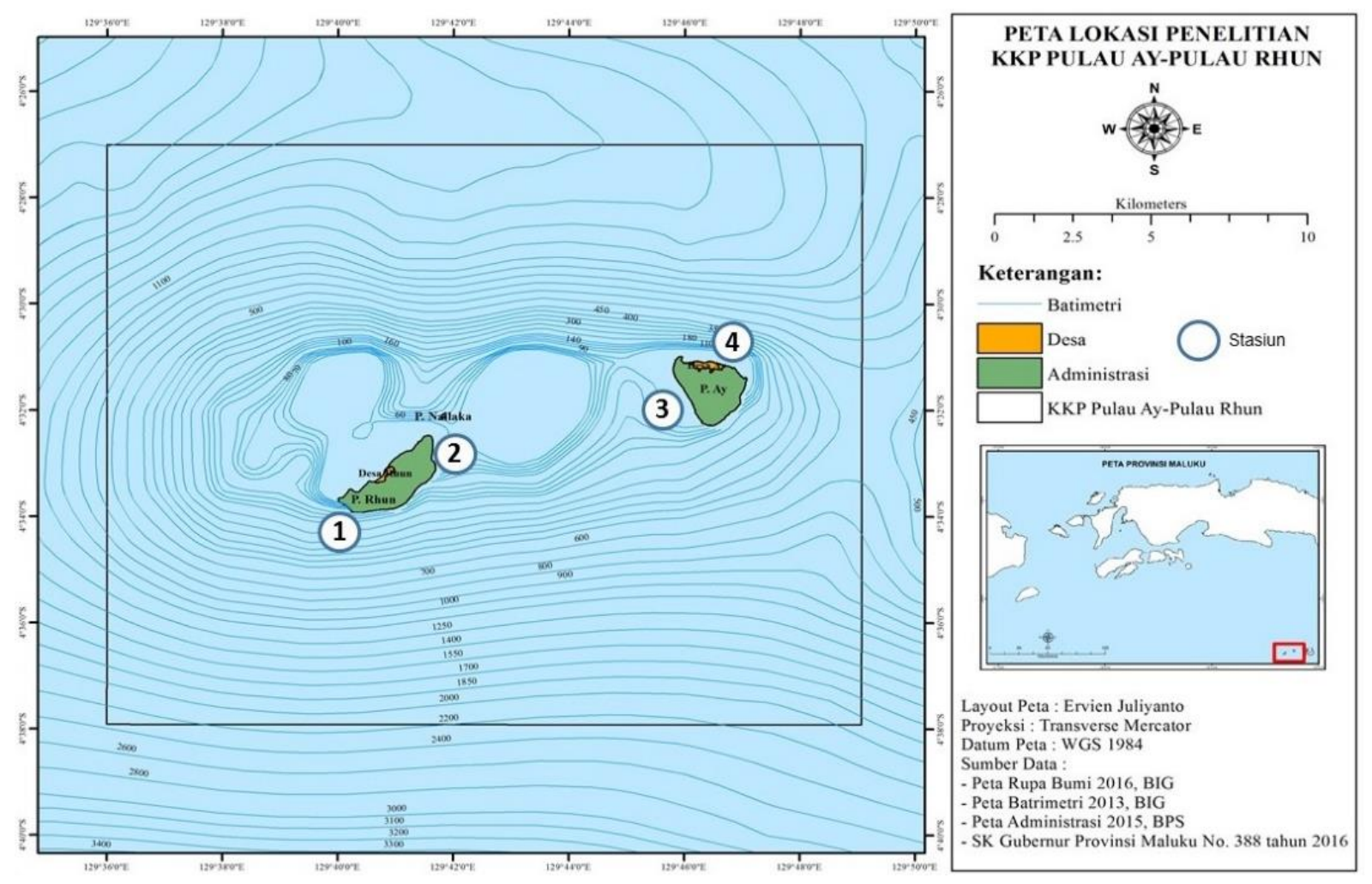

Figure 1. Research location and station at Ay and Rhun Islands (Julyanto, 2019).

Table 1. Coordinat point of observation station.

\begin{tabular}{lcc}
\hline \multicolumn{1}{c}{ Stations } & South & East \\
\hline Tanjung Noret (Rhun island) & S $4.56530^{\circ}$ & E $129.66949^{\circ}$ \\
Nailaka P. (Rhun island) & S $4.53789^{\circ}$ & E $129.69902^{\circ}$ \\
Batu Belang (West island Ay) & S $4.52323^{\circ}$ & E $129.76141^{\circ}$ \\
Batu Jatuh (East island Ay) & S.4.51786 & E $129.77640^{\circ}$ \\
\hline
\end{tabular}

ikan (fish length estimation) juga dilakukan pada saat pengumpulan data ikan dibawah air. Jumlah transek yang digunakan sepanjang $5 \mathrm{~m}$ x $50 \mathrm{~m}$ pada kedalaman $10 \mathrm{~m}$ di setiap stasiun pengamatan (Wilson \& Green, 2009).

\subsection{Analisis Data}

Data yang dikumpulkan selanjutnya dianalisis untuk mengetahui perubahan kelimpahan ikan karang, perubahan biomassa ikan karang, perubahan status tropik ikan karang berdasarkan biomassa serta perubahan ukuran panjang ikan karang sebelum dan sesudah pencadangan KKPD Pulau Ay dan Pulau Rhun. Analisis dilakukan dengan data primer dan data sekunder (Bengen, 2000).

Kelimpahan ikan karang dihitung berdasarkan konversi jumlah individu ikan per satuan luas transek menjadi individu per hektar (Odum, 1971):

$$
X i=\frac{n i}{A}
$$

Keterangan: $\mathrm{Xi}=$ kelimpahan komunitas terpilih $\mathrm{ke}-\mathrm{i}$ (ind/koloni $/ \mathrm{m}^{2}$; ni = jumlah total komunitas terpilih pada stasiun pengamatan ke-i; A = luas transek pengamatan.

Biomassa ikan karang dihitung dengan menduga berat ikan dalam luasan transek tertentu berdasarkan estimasi ukuran 
panjang ikan. Hubungan panjang dan berat ikan dapat dihitung berdasarkan Kulbicki et al. (2005):

$W=a L^{b}$

Keterangan: $\mathrm{W}=$ berat ikan dalam $(\mathrm{gr}) ; \mathrm{L}=$ panjang fork (FL) ikan dalam (cm); $a, b=$ nilai konstanta yang dihitung untuk setiap spesies dari famili yang didapat.

Biomassa ikan karang tiap stasiun dirata-ratakan (Wilson \& Green, 2009) dengan rumus:

Biomassa $=\mathrm{W} / \mathrm{A}$

Keterangan: $\mathrm{W}=$ berat ikan per unit transek dalam (gr); $\mathrm{A}=$ areal unit transek $\left(\mathrm{m}^{2}\right)$.

Penghitungan biomassa ikan dibuat menjadi lebih mudah dengan mengubah satuan berat ikan kedalam kilogram $(\mathrm{kg})$ dan areal unit transek kedalam hektar (ha). Total biomassa ikan karang di setiap stasiun pengamatan didapatkan dari penjumlahan biomassa rata-rata dari masing-masing famili ikan karang yang dicatat pada stasiun tersebut.

Table 2. Category of reef fish biomass (Giyanto et al., 2017).

\begin{tabular}{cll}
\hline No. & Category & \multicolumn{1}{c}{ Criteria } \\
\hline 1. & Low & $>1940 \mathrm{~kg} / \mathrm{ha}$ \\
2. & Medium & $970 \mathrm{~kg} / \mathrm{ha} \leq$ Reef fish \\
& & $\begin{array}{l}\text { total biomass } \leq 1940 \\
\mathrm{~kg} / \mathrm{ha}\end{array}$ \\
3. High & $\begin{array}{l}\text { Reef fish biomass } \geq 1940 \\
\mathrm{~kg} / \mathrm{ha}\end{array}$ \\
\hline
\end{tabular}

Perubahan status tropik ikan karang dihitung berdasarkan biomassa famili ikan karang kelompok karnivora (Serranidae, Carangidae, Lutjanidae, Lethrinidae, Labridae, Haemulidae dan Sphyraenidae), kelompok herbivora (Siganidae, Achanturidae dan Scaridae) dan kelompok planktivora (Achanturidae dari genus Naso) pada setiap stasiun pengamatan (Giyanto et al., 2014). Perubahan ukuran ikan dihitung berdasarkan jumlah persentase ikan besar dengan panjang $\geq 35 \mathrm{~cm}$ dan ikan kecil dengan panjang $<35 \mathrm{~cm}$ pada setiap stasiun pengamatan. Panjang ikan ini diperoleh dengan melakukan fish length estimation dibawah air (Wilson \& Green, 2009).

\section{HASIL DAN PEMBAHASAN}

\subsection{Kelimpahan Ikan Karang} Berdasarkan Stasiun Pengamatan

Kelimpahan ikan berdasarkan data sekunder dan hasil pengamatan terhadap 10 famili ikan karang target dan ekonomis penting yaitu Achanturidae (kulit pasir), Carangidae (kuwe), Haemulidae (bibir tebal), Labridae (napoleon), Lethrinidae (lencam), Lutjanidae (kakap), Scaridae (kakak tua), Serranidae (kerapu), Siganidae (baronang), dan Sphyraenidae (barakuda) di empat stasiun pengamatan dalam KKPD Pulau Ay dan Pulau Rhun pada tahun 2012-2018 masuk dalam kategori melimpah. Kelimpahan ikan meningkat di semua stasiun pengamatan pada tahun 2012 dan 2015 sebelum Pulau Ay dan Pulau Rhun dicadangkan sebagai KKPD. Namun sebaliknya sesudah dicadangkan sebagai KKPD, pada tahun 2017 dan 2018, kelimpahan ikan mengalami penurunan, kecuali stasiun pengamatan Nailaka (Pulau Rhun) mengalami peningkatan (Figure 2).

Penurunan kelimpahan ikan diseluruh lokasi pengamatan, kecuali Nailaka disebabkan karena laju penangkapan ikan oleh nelayan masih terus terjadi setelah pencadangan KKPD. Pada saat penelitian dilakukan pada saat musim timur telah dimulai sehingga nelayan tidak banyak menangkap di sekitar Nailaka (Pulau Rhun) yang terletak di sebelah timur, namun menangkap di sebelah barat. Masyarakat di Pulau Rhun telah mencadangkan Nailaka sebagai lokasi wisata bahari sehingga mengurangi kegiatan penangkapan ikan. Penyebab lainnya adalah belum adanya sistim zonasi seperti zona perikanan berkelanjutan, zona inti, zona 


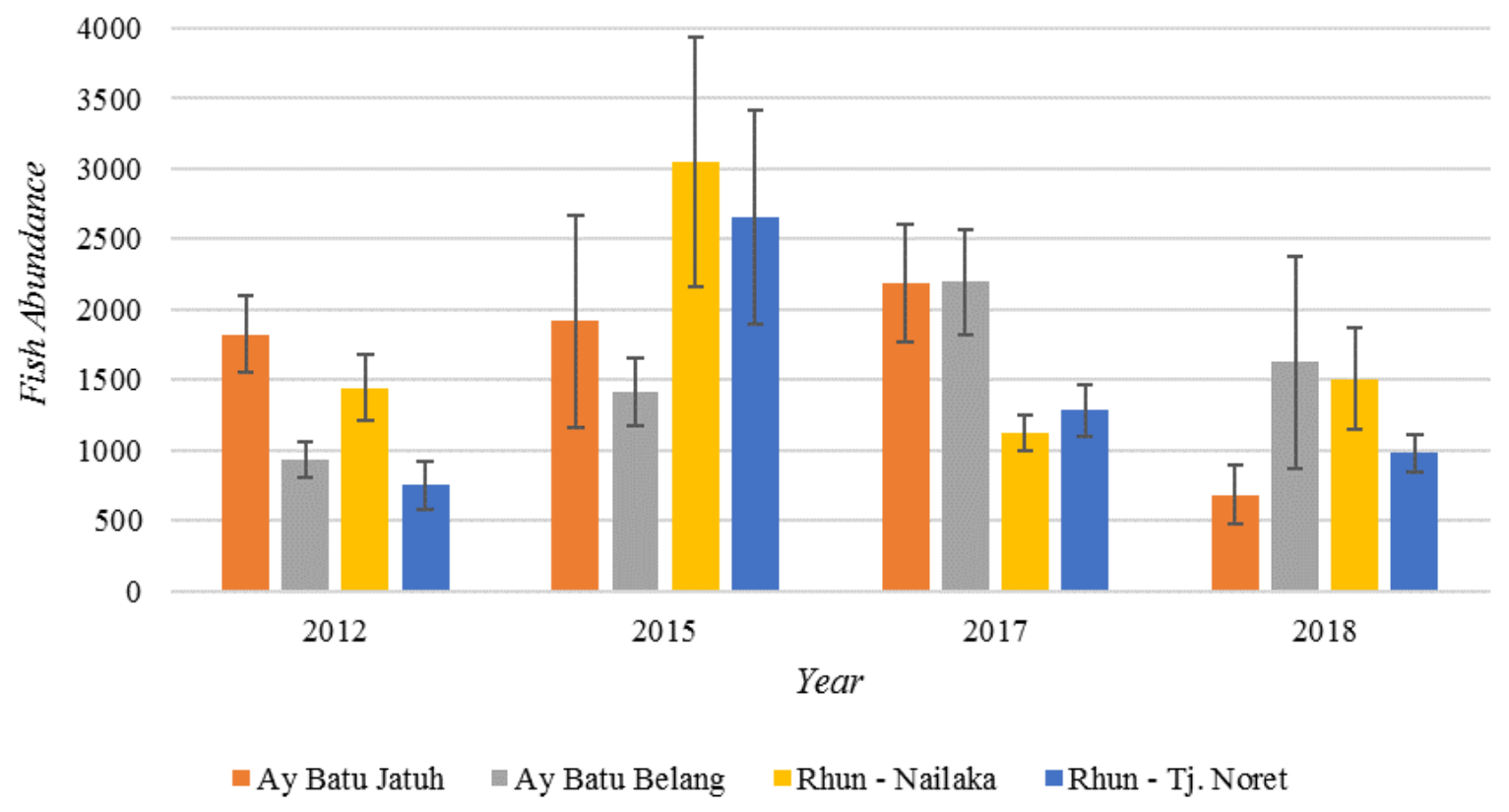

Figure 2. Average of reef fish target abundance (10 family) at four observation point in Ay and Rhun Islands MPA.

pemanfaatan terbatas (wisata bahari), dan zona lainnya berikut dengan aturan atau sanksi sehingga nelayan masih dapat secara bebas menangkap ikan diseluruh perairan Pulau Ay dan Pulau Rhun. Secara temporal, kelimpahan rata-rata tertinggi berada pada tahun 2015 sebesar 2.323 ind/ha dan terendah pada tahun 2018 sebesar 1.199 ind/ha. Pencadangan KKPD Pulau Ay dan Pulau Rhun berdasarkan kelimpahan ikan baru memberi dampak positif pada stasiun pengamatan Nailaka di Pulau Rhun dibandingkan stasiun pengamat-an lainnya.

\subsection{Kelimpahan Ikan Berdasarkan Famili}

Kelimpahan ikan karang berdasarkan famili (10 ikan target) tahun 2012 sebelum pencadangan KKPD Pulau Ay dan Pulau Rhun, didominasi oleh famili Lutjanidae (kakap) sebesar 406 ind/ha dan mengalami penurunan pada tahun 2015 menjadi 282 ind/ha. Kondisi ini disebabkan karena laju penangkapan yang cukup tinggi terhadap ikan kakap dan kerapu oleh nelayan untuk dijual kepada pengepul karamba. Sebaliknya setelah pencadangan KKPD, karamba tidak diijinkan berada di dalam perairan Pulau Ay dan Pulau Rhun yang menyebabkan famili Lutjanidae (kakap) mengalami peningkatan sehingga kembali mendominasi pada tahun 2017 (405 ind/ha) dan 2018 (628 ind/ha). Namun tidak demikian dengan laju penangkapan terhadap ikan kerapu yang masih cukup tinggi setelah pencadangan KKPD.

Ekosistem padang lamun memiliki korelasi yang kuat dengan keberadaan ikan famili Siganidae dan hebivora lainnya (Fakhri et al., 2016). Saat pencadangan KKPD Pulau Ay dan Pulau Rhun pada tahun 2016, terdapat wilayah ekosistem padang lamun yang ditutup sebagai daerah sasi oleh masyarakat. Penutupan ekosistem lamun dari akses penangkapan ikan tersebut dapat memberikan kesempatan bagi ikan dari famili Siganidae untuk berkembang dan tumbuh. Pada tahun 2017 hampir semua famili ikan target mengalami penurunan kelimpahan setelah pencadangan KKPD, kecuali famili Lutjanidae (kakap) dan Siganidae (baronang). Hal ini menunjukan bahwa beberapa famili ikan karang mengalami tekanan pemanfaatan di KKPD 


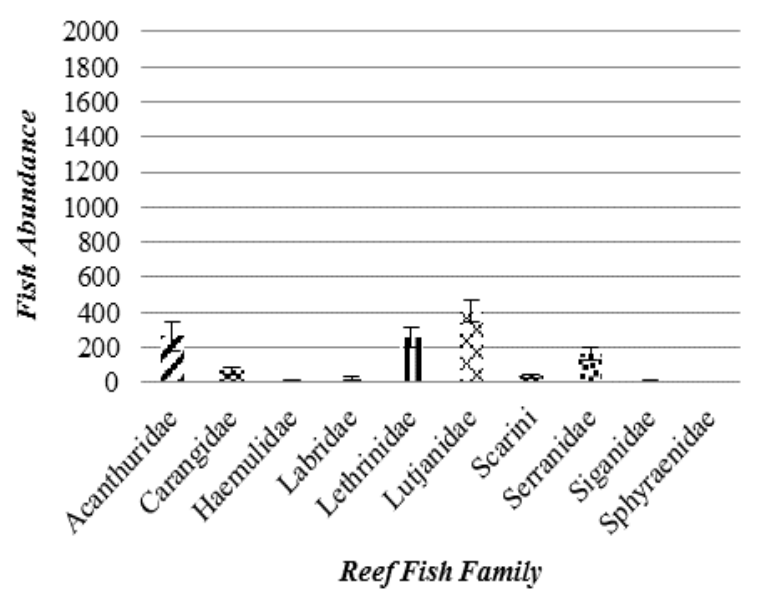

(a)

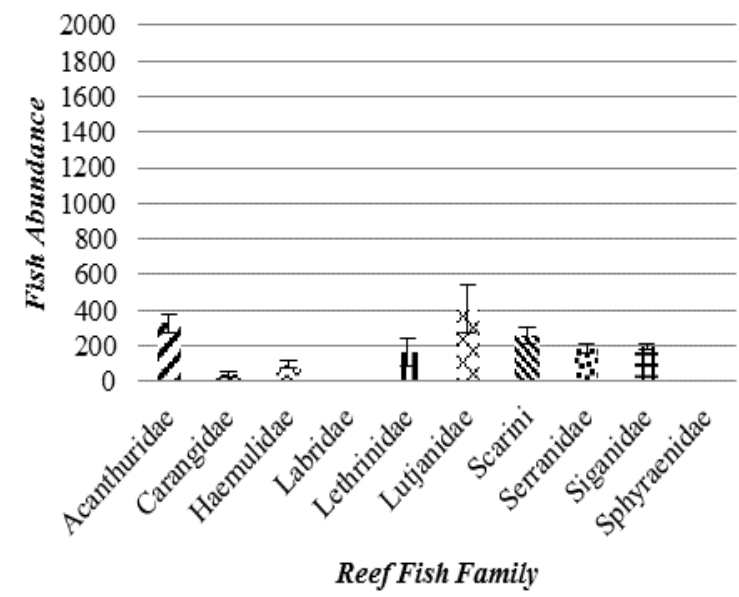

(c)

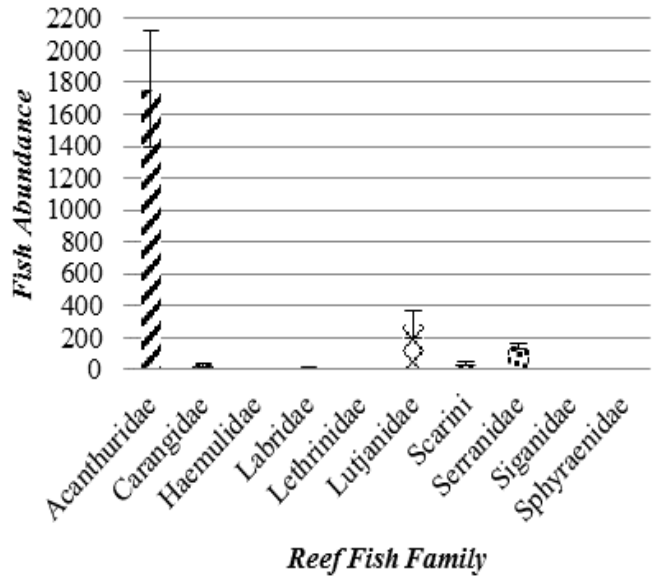

(b)

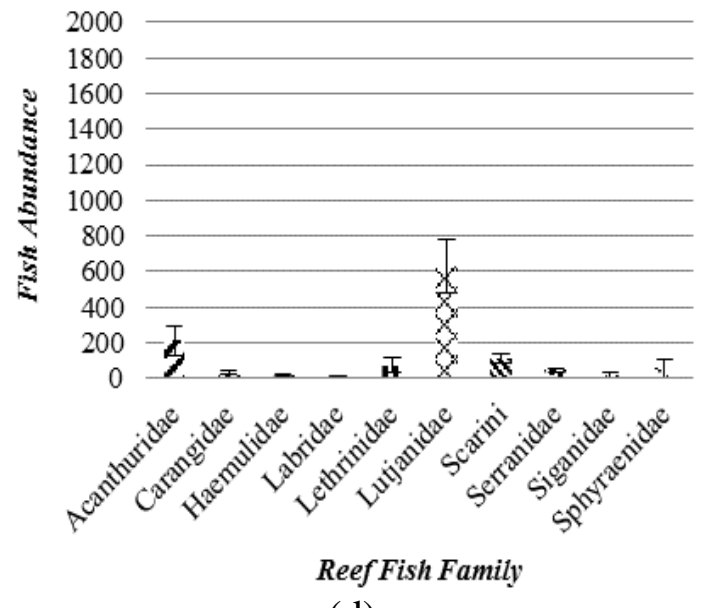

(d)

Figure 3. Reef fish abundance based on 10 family target and economical important in Ay and Rhun Island MPA 2012 (a), 2015 (b), 2017 (c), and 2018 (d).

Pulau Ay dan Pulau Rhun kecuali ikan dari famili Lutjanidae (kakap).

\subsection{Biomassa Ikan Karang \\ Berdasarkan Stasiun Pengamatan}

Berdasarkan data sekunder dan hasil pengamatan (Figure 4), total biomassa ikan karang di empat stasiun pengamatan dalam KKPD Pulau Ay dan Pulau Rhun dari tahun 2012-2018 masuk dalam kategori sedang hingga tinggi (Giyanto et al., 2017). Biomassa ikan karang target meningkat hampir di semua stasiun pengamatan kecuali di stasiun Batu Jatuh (Ay Utara) mengalami penurunan setelah pencadangan KKPD. Kondisi ini terjadi disebabkan karena stasiun
Batu Jatuh merupakan lokasi penangkapan ikan terdekat bagi nelayan Pulau Ay dan letaknya berada di depan kampung sebelah barat sehingga mudah untuk dijangkau. Tahun 2012, sebelum Pulau Ay dan Pulau Rhun dicadangkan sebagai KKPD total biomassa ikan karang sebesar 3582,3 kg/ha dan mengalami penurunan pada tahun 2015 menjadi 1202,3 kg/ha. Hal ini menunjukan telah terjadi tekanan terhadap ikan karang di Pulau Ay dan Pulau Rhun. Namun setelah pencadangan KKPD, total biomassa ikan karang meningkat. Tahun 2018, total biomassa ikan karang mencapai 2670,7 $\mathrm{kg} / \mathrm{ha}$, masuk dalam kategori tinggi (Giyanto et al., 2017). 


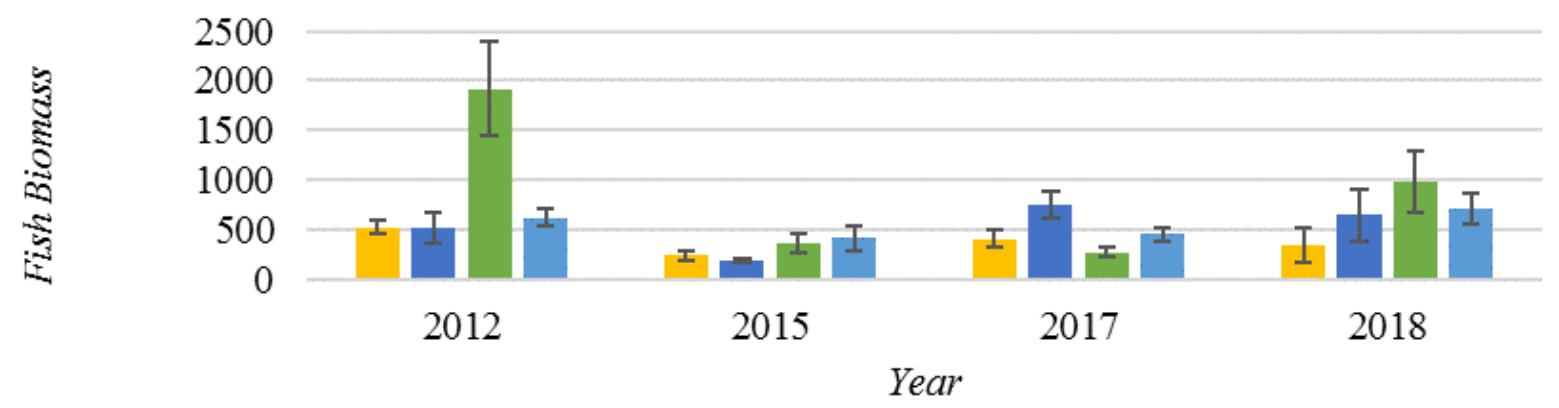

$\square$ Ay Batu Jatuh $\quad$ Ay Batu Belang $\quad$ Rhun - Nailaka $\quad$ Rhun - Tj. Noret

Figure 4. Average of reef fish target biomass (10 family) at four observation points in Ay and Rhun Islands MPA.

3.4. Biomassa Ikan Berdasarkan Famili

Biomassa ikan karang berdasarkan famili (10 ikan target) pada tahun 2012 didominasi oleh famili Labridae (napoleon) dan Lutjanidae (kakap) masing-masing sebesar $356,4 \mathrm{~kg} / \mathrm{ha}$ dan $207,7 \mathrm{~kg} / \mathrm{ha}$. Namun mengalami penurunan pada tahun 2015 menjadi $1,8 \mathrm{~kg} / \mathrm{ha}$ dan $69,5 \mathrm{~kg} / \mathrm{ha}$. Hal ini menunjukan kedua famili ikan karang tersebut mengalami tekanan dan digantikan dominasinya oleh ikan dari famili Achanturidae (kulit pasir). Sebaliknya pada tahun 2017 setelah Pulau Ay dan Pulau Rhun dicadangkan sebagai KKPD biomassa ikan karang famili Labridae (napoleon) dan Lutjanidae (kakap) mengalami peningkatan sebesar $41,7 \mathrm{~kg} / \mathrm{ha}$ dan $80,1 \mathrm{~kg} / \mathrm{ha}$. Ikan dari famili Lutjanidae (kakap) terus mengalami peningkatan dan kembali mendominasi pada tahun 2018 dengan biomassa sebesar 329,7 $\mathrm{kg} / \mathrm{ha}$ (Figure 5).

Berdasarkan lima famili ikan karang target yang memiliki biomassa tertinggi menunjukan bahwa terjadi peningkatan biomassa pada ikan dari famili Lutjanidae (kakap), Labridae (napoleon) dan Carangidae (kuwe) setelah pencadangan KKPD Pulau Ay dan Pulau Rhun. Jenis ikan karang lainnya adalah famili Serranidae (kerapu) dengan biomassa yang relatif stabil setelah pencadangan KKPD. Namun terjadi penurunan biomassa pada ikan karang dari famili Achanturidae (kulit pasir). Penurunan tersebut disebabkan karena laju penangkapan yang tinggi terhadap ikan kulit pasir, terutama oleh kapal-kapal ikan penangkap tuna untuk dijadikan umpan. Ikan karang famili Achanturidae bukan merupakan jenis ikan yang dilindungi di dalam KKPD Pulau Ay dan Pulau Rhun (Figure 6).

\subsection{Status Tropik Ikan Karang}

Berdasarkan analisis data sekunder dan primer (Figure 7), status tropik ikan karang berdasarkan biomassa ikan mengalami fluktuasi setiap tahunnya. Tahun 2012 sebelum Pulau Ay dan Pulau Rhun dicadangkan menjadi KKPD, status tropik kelompok ikan karnivora mendominasi, namun menurun pada tahun 2015 dan digantikan oleh status tropik ikan kelompok planktivora. Kondisi tersebut menunjukan telah terjadi gangguan terhadap keseimbangan status tropik ikan karang di Pulau Ay dan Pulau Rhun (Obura \& Grimsdit, 2009).

Tahun 2017 setelah pencadangan KKPD, status tropik kelompok ikan karnivora dan herbivora kembali mendominasi dan cukup berimbang dibandingkan kelompok planktivora. Tahun 2018 kelompok ikan karnivora kembali mendominasi status tropik. Berdasarkan status tropiknya terlihat bahwa kondisi ikan karang di KKPD P. Ay dan Rhun berada dalam kondisi yang seimbang antara ketiga kelompok tropik. Keberadaan kelompok ikan karnivora sebagai predator befungsi untuk menjaga keseimbangan ekosistem 


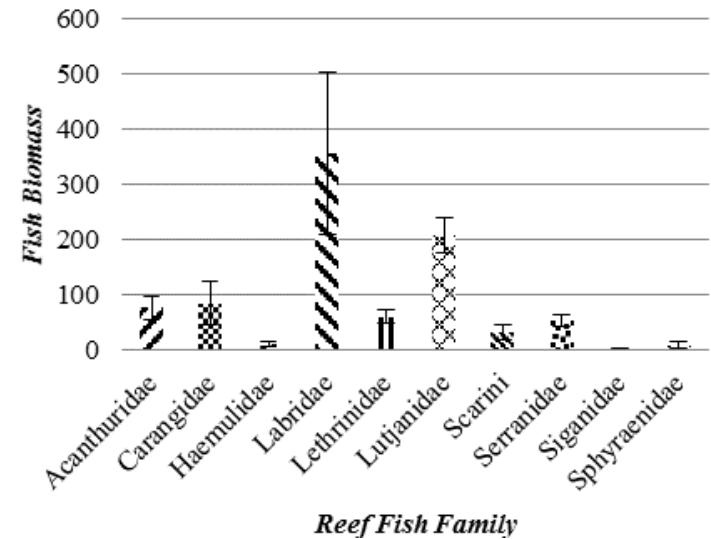

(a)

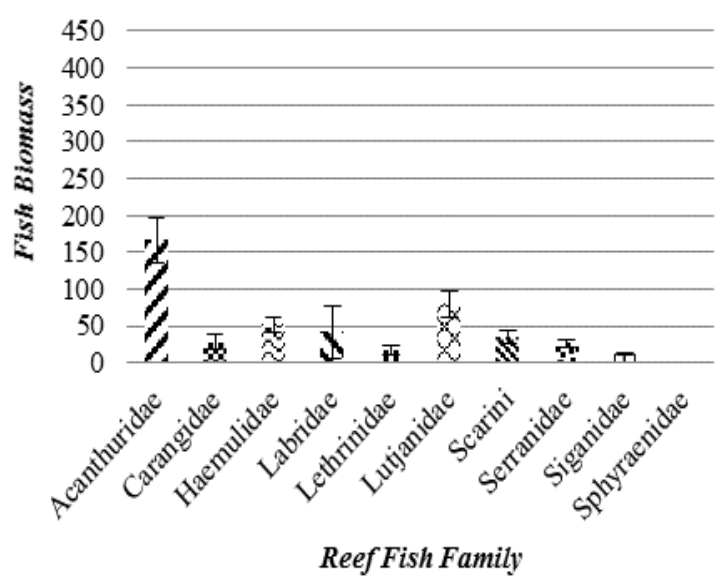

(c)

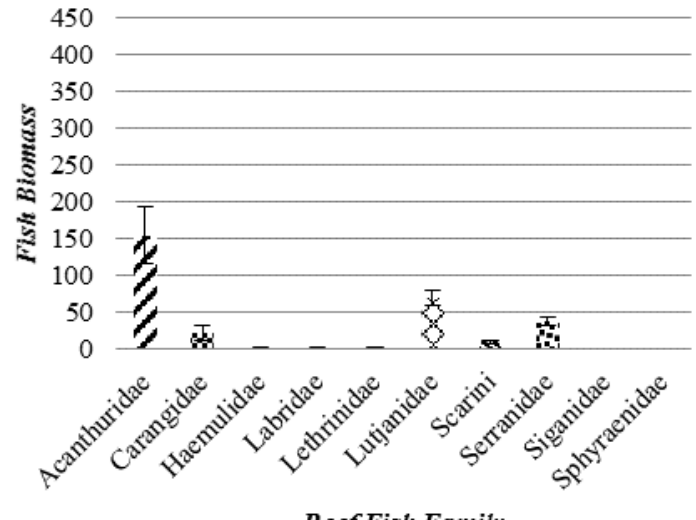

(b)

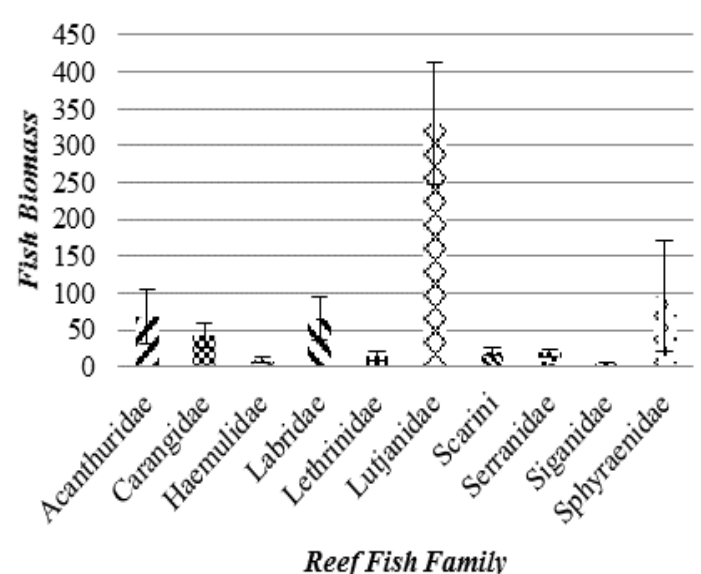

(d)

Figure 5. Reef fish biomass based on 10 family target and economical important in Ay and Rhun Islands MPA 2012 (a), 2015 (b), 2017 (c), and 2018 (d).

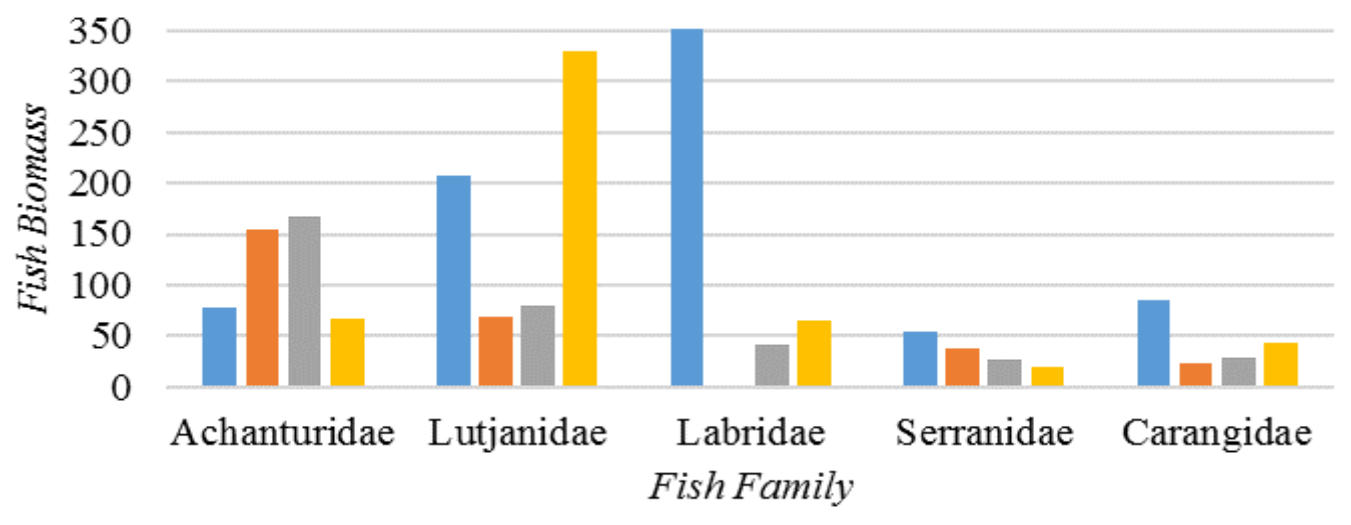

$$
\square 2012 \square 2015 \square 2017 \quad \square 2018
$$

Figure 6. Reef fish target biomass (five highest family) at four observation points in Ay and Rhun Islands MPA. 


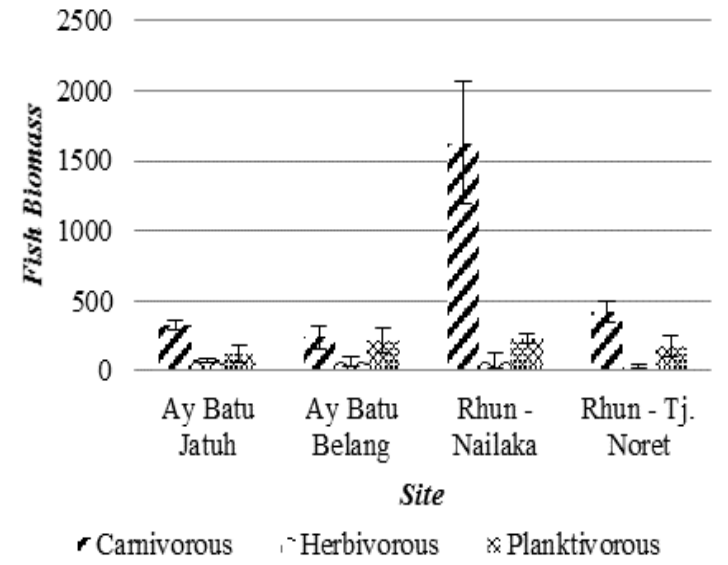

(a)

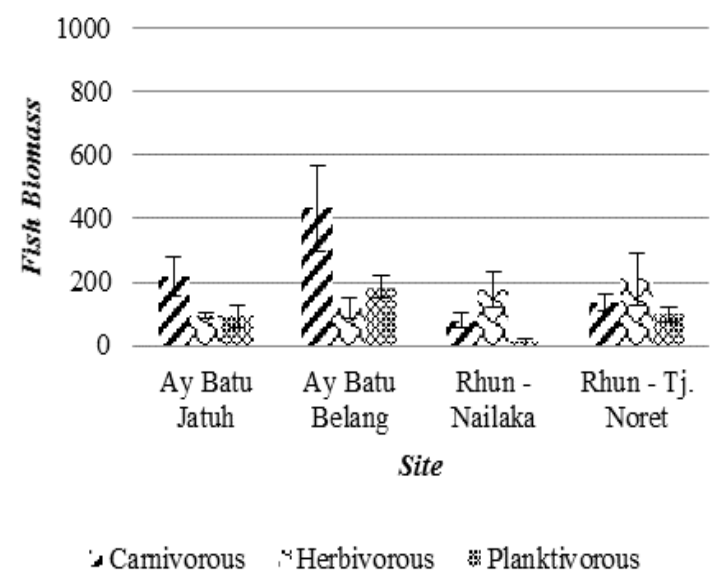

(c)

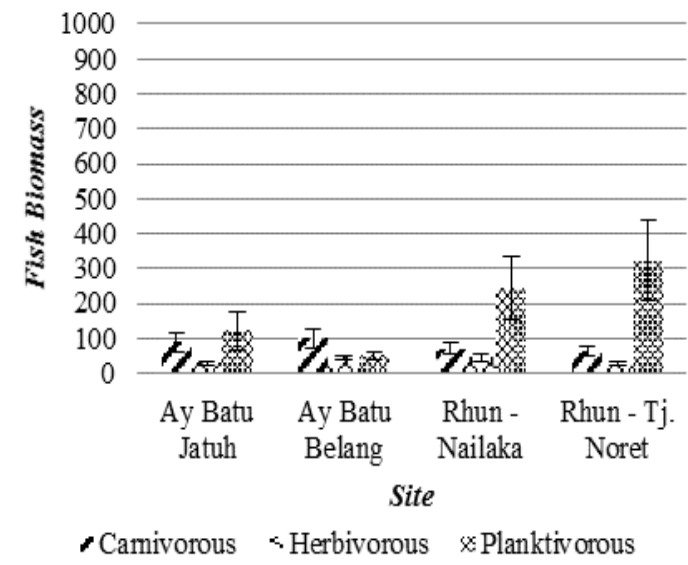

(b)

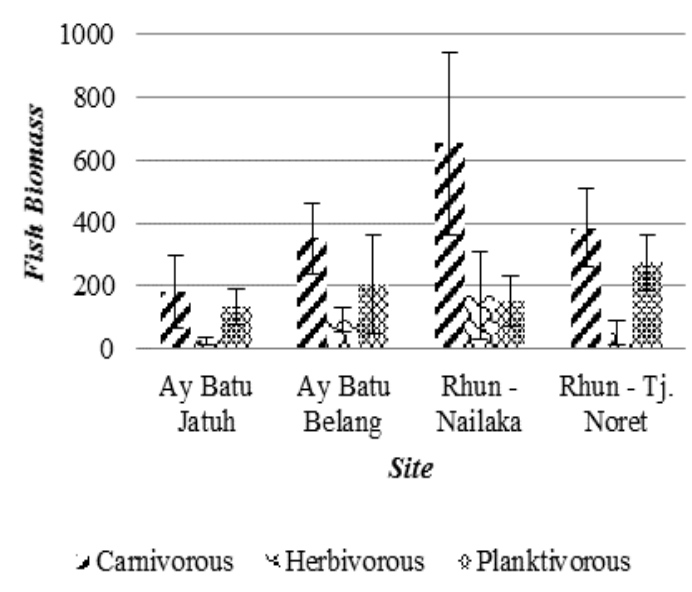

(d)

Figure 7. Level of reeffish tropic status based on 10 family target and economical important in Ay and Rhun Islands MPA 2012 (a), 2015 (b), 2017 (c) and 2018 (d).

dengan mengontrol kelompok ikan lain yang status tropiknya lebih rendah (Obura \& Grimsdith, 2009).

\subsection{Komposisi Ukuran Panjang Ikan Karang}

Ukuran ikan karang dapat menggambarkan kondisi populasi ikan karang di sebuah perairan (Wilson \& Green, 2009). Pada tahun 2012 sebelum Pulau Ay dan Pulau Rhun dicadangkan sebagai KKPD ukuran panjang ikan karang didominasi ikan karang berukuran besar $(\geq 35 \mathrm{~cm})$ yaitu sebesar $69,1 \%$. Komposisi ikan karang berdasarkan ukuran panjang berubah dan didominasi oleh ikan kecil sebesar 79,9\% pada tahun 2015. Kondisi tersebut meng- gambarkan bahwa populasi ikan karang di Pulau Ay dan Pulau Rhun telah mengalami tekanan dengan semakin berkurangnya ikan besar.

Tahun 2017 setelah pencadangan KKPD komposisi ikan karang belum mengalami perubahan dan masih didominasi ikan kecil sebesar 79,9\%. Hal ini me-nunjukan pencadangan KKPD belum membawa dampak terhadap komposisi ukuran ikan karang. Namun pada tahun 2018 pada saat penelitian ini dilakukan, komposisi ukuran ikan berubah kembali didominasi ikan besar dengan persentase $58,6 \%$ (Figure 8). Kondisi tersebut menggambarkan keberadaan KKPD P. Ay dan P. Rhun telah berdampak positif terhadap komposisi ukuran panjang ikan. 


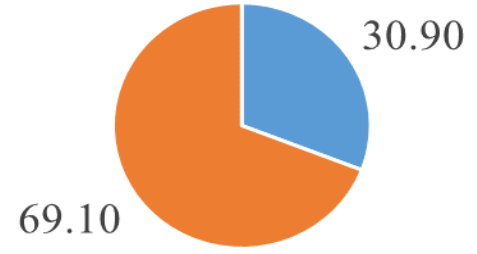

(a)

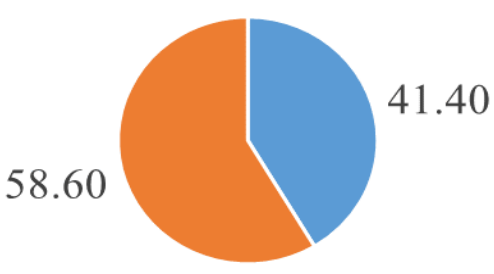

(c)

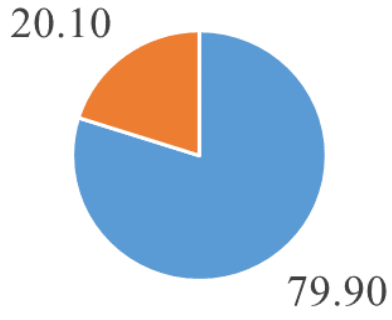

(b)

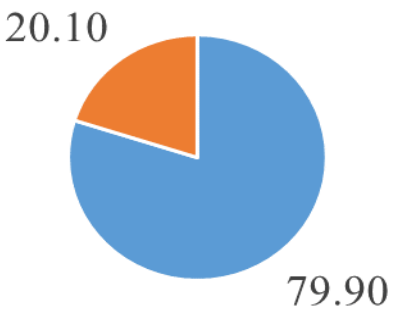

(d)

Figure 8. Reef fish length size composition based on 10 family target and economical important in Ay and Rhun Islands MPA 2012 (a), 2015 (b), 2017 (c) and 2018 (d).

\section{KESIMPULAN}

Kelimpahan ikan karang target dan ekonomis penting (10 famili) mengalami penurunan sesudah pencadangan KKPD, kecuali ikan dari famili Lutjanidae (kakap). Kondisi tersebut menunjukan populasi ikan karang di P. Ay dan P. Rhun mengalami tekanan.

Total biomassa ikan karang target dan ekonomis penting (10 famili) mengalami peningkatan setelah pencadangan KKPD. Kondisi ini menunjukan pencadangan KKPD berpengaruh positif terhadap total biomassa ikan karang di Pulau Ay dan Pulau Rhun.

Status tropik ikan karang di KKPD Pulau Ay dan Pulau Rhun berdasarkan ikan target dan ekonomis penting (10 famili) berfluktuasi. Setelah pencadangan KKPD,

status tropik ikan karang didominasi kembali oleh kelompok karnivora namun berada dalam kondisi yang proporsional dengan kelompok tropik lainnya. Kondisi ini menunjukan pencadangan KKPD Pulau Ay dan Pulau Rhun memberikan dampak postif terhadap status tropik ikan karang.
Komposisi ikan karang berdasarkan ukuran panjang ikan di dominasi kembali oleh ikan berukuran besar setelah pencadangan KKPD. Kondisi ini menunjukan bahwa KKPD Pulau Ay dan Pulau Rhun berpengaruh positif terhadap ukuran panjang ikan.

\section{UCAPAN TERIMA KASIH}

Terima kasih kepada Direktur Eksekutif CTC atas dukungan data sekunder, bantuan pendanaan, dan tim lapangan sehingga penelitian dapat dilaksanakan. Ucapan terima kasih juga disampaikan kepada Pemerintah Propinsi Maluku, Raja Negeri dan masyarakat Pulau Ay dan Pulau Rhun atas bantuannya selama penelitian dilakukan.

\section{DAFTAR PUSTAKA}

Allen, G.R. \& R. Steene. 1996. Indo pacific coral reef field guide. Tropical Reef Research. Singapore. 378 p.

Bengen, D.G. 2000. Sinopsis teknik pengambilan contoh dan analisa data 
biofisik sumberdaya pesisir. Bogor (ID): Pusat Kajian Sumber daya Pesisir dan Lautan, Institut Pertanian Bogor. Bogor. $31 \mathrm{p}$.

Carter, E., A. Soemodinoto, \& A. White. 2010. Panduan untuk meningkatkan efektivitas pengelolaan kawasan konservasi laut di Indonesia. The Nature Conservancy Indonesia. Bali. $67 \mathrm{p}$.

English, S.C., Wilkinson, \& V. Baker. 1997. Survey manual for tropical marine resources. Australian Institute of Marine Science, Townsville. Australia. 390 p.

Fakhri, S.A., I. Riyantini, D.P. Juliandri, \& H. Hamdani. 2016. Korelasi kelimpahan ikan baronang (Siganus spp) dengan ekosistem padang lamun di Perairan Pulau Pramuka Taman Nasional Kepulauan Seribu. $J$. Perikanan Kelautan, 8(1): 165-171. http://doi.org/13954-31197-1-SM

Giyanto, A.E.W. Manuputty, M. Abrar, R.M. Siringoringo, S.R. Suharti, K. Wibowo, I.N. Edrus, U.Y. Arbi, H.A.W. Cappenberg, H.F. Sihaloho, Y. Tuti, \& D. Zulfianita. 2014. Panduan Monitoring Kesehatan Terumbu Karang. COREMAP CTI LIPI. Jakarta.

Giyanto, P. Mumby, N. Dhewani, M. Abrar, \& M.Y. Iswari. 2017. Indeks kesehatan terumbu karang Indonesia. Pusat Penelitian Oseanografi - LIPI. Jakarta. 99 p.

Green, A.L. \& D.R. Bellwood. 2009. Monitoring functional groups of herbivora reef fishes as indicators of coral reef resilience $-\mathrm{A}$ practical guide for coral reef managers in the Asia Pacific region. IUCN working group on Climate Change and Coral Reefs. Switzerland. 70 p.

Huffard, C.L., M.V. Erdmann, \& T.R.P. Gunawan. 2012. Geographic priorities for marine biodiversity conservation in Indonesia.
Kementrian Kelautan dan Perikanan. Jakarta. 105 p.

Hukom, F.D., F. Yulianda, D.G. Bengen, \& M.M Kamal. 2019. Efektivitas zonasi dalam pengelolaan perikanan karang di kawasan konservasi perairan Selat Dampier, Raja Ampat. J. Kebijakan Sosek KP, 9(1): 93-103. http://doi.org/10.15578/jksekp.v9i2.7 661

Kementerian Kelautan dan Perikanan (KKP). Peraturan Pemerintah No.60 Tahun 2007 Tentang Konservasi Sumberdaya Ikan. KKP. Jakarta. 35 p.

Kulbicki, M., N. Guillemot, \& M. Ahmad. 2005. A general approach to lengthweight relationships for New Caledonian lagoon fishes. Cybium, 29: 235-252.

Muljadi, A.H., F. Rijoly, \& J. Subijanto. 2012. Reef fish diversity in the Banda Naira Islands, Indonesia. Marine Rapid Assesment di Kepulauan Banda. Coral Triangle Center. 88-97. 166 p.

Obura, D.O. \& G. Grimsdith. 2009. Resilience Assessment of coral reefs - Assessment protocol for coral reefs, focusing on coral bleaching and thermal stress. IUCN working group on Climate Change and Coral Reefs. IUCN. Switzerland. 70 p.

Odum, E.P. 1971. Fundamental of Ecology. W.B. Sounders Company. London. $585 \mathrm{p}$.

Skoglund, S. 2014. Effect of different marine protection levels on fish communities in tropical seagrass beds and coral reefs. Stockholms Universited. 2-5. $32 \mathrm{p}$.

Welly, M., R. Djohani, Suharsono, A.L. Green, A. Muljadi, M. Korebima, Y. Hehuat, R. Alik, \& N. Rijoli. 2013. Marine Rapid Assessment of the Banda Islands, Maluku Tengah, Indonesia. Coral Triangle Center. Bali. 159 p. 
Pengaruh Kawasan Konservasi Perairan Terhadap Populasi Ikan . . .

Wilson, J.R. \& A.L. Green. 2009. Biological monitoring methods for assessing coral reef health and management

Received :01 March 2019 effectiveness of Marine Protected Reviewed : 11 March 2020 Areas in Indonesia. TNC Indonesia Marine Program. 13-22. 44 p. 